\title{
Laboratory Markers of Liver Damage in Chronic Hepatitis C
}

\author{
DOI: 10.17691/stm2017.9.3.12
}

Received September 15, 2015

I.A. Bulatova, PhD, Associated Professor, Department of Clinical Laboratory Diagnostics;

A.P. Shchyokotova, MD, DSc, Head of the Department of Clinical Laboratory Diagnostics:

N.I. Nasibullina, PhD Student, Department of Internal Diseases and Polyclinic Therapy;

S.V. Paducheva, Teaching Assistant, Department of Clinical Laboratory Diagnostics;

V.V. Shchyokotov, MD, DSc, Professor, Head of the Department of Internal Diseases and Polyclinic Therapy

Perm State Medical University named after Academician E.A. Wagner, 26 Petropavlovskaya St., Perm, 614990 ,

Russian Federation

The aim of the investigation was to assess the availability of a combined study of biochemical tests, hyaluronic acid (HA), alphafetoprotein (AFP), malondialdehyde (MDA), catalase, cytokines, and leptin to determine the liver damage severity (fibrosis and cirrhosis stages) in patients with chronic hepatitis $\mathrm{C}(\mathrm{CHC})$.

Materials and Methods. The study involved 100 patients with $\mathrm{CHC}$ during a reactivation stage. A control group consisted of 30 apparently healthy subjects. Hepatic density was measured by ultrasound elastography. In blood of $\mathrm{CHC}$ patients we determined biochemical measurements of transaminase and albumin, platelet count, HA concentration, tumor necrosis factor (TNF- $\alpha$ ), vascular endothelial growth factor (VEGF), leptin, AFP level, MDA, and catalase activity.

Results. CHC reactivation is characterized by the increase of HA $(p=0.01)$, AFP $(p=0.02)$, MDA $(p<0.001)$, VEGF $(p<0.001)$, TNF- $a$ $(p=0.001)$ and leptin $(p=0.001)$ with a simultaneous decrease of platelet count $(p=0.04)$ and catalase decreased activity $(p<0.001)$. In CHC, all fibrosis stages in the liver enable to stratify the serum markers of HA and TNF- $\alpha$, that is confirmed by their direct significant correlations with hepatic density according to ultrasound elastography $(r=0.42 ; p=0.001$ and $r=0.41 ; p=0.001$, respectively). The most pronounced increase in AFP, VEGF, MDA, and leptin in simultaneous decrease in albumin synthesis, catalase activity, and platelet count is observed in severe fibrosis.

Conclusion. Serum concentrations of HA and TNF- $\alpha$ in CHC show the degree of hepatic tissue damage and can be used to stratify hepatic fibrosis stages. AFP, VEGF, MDA albumin, catalase, leptin concentration and platelet count can be used as accessory tests to diagnose severe fibrosis in $\mathrm{CHC}$ patients.

Key words: hepatitis C; hepatic fibrosis; liver cirrhosis; hyaluronic acid; liver damage markers.

Despite the background experience of managing patients with chronic hepatitis $\mathrm{C}(\mathrm{CHC})$, there are evident problems of great concern, which are related to the infection: high incidence of chronic forms, a long-term asymptomatic disease course, late stage manifestations (liver cirrhosis), clear association with hepatocellular carcinoma. Chronic $\mathrm{CHC}$ infection is able to initiate fibrosis processes in the liver after 20-30 years of cirrhosis in $20-45 \%$ patients, and hepatocellular carcinoma in 5-15\% patients [1-4].

The major task in managing patients with $\mathrm{CHC}$ is the assessment of the degree of necroinflammatory changes and fibrosis extent in hepatic tissue. Liver needle biopsy is a gold standard of $\mathrm{CHC}$ diagnosis. It enables to determine the degree of inflammation activity and fibrosis intensity. Like any invasive method, biopsy requires to observe the rules of the procedure in specialized facilities and a qualified staff to interpret findings, since there is the risk of developing a variety of complications [1,5]. Currently, the capabilities of noninvasive evaluation and liver fibrosis monitoring are being studied extensively. There have been published many works showing the data on diagnostic significance of serum markers of fibrosis, which enable to both assess $\mathrm{CHC}$ stage and fibrinogenesis activity in the liver, such as hyaluronic acid (HA), 1V type collagen [6]. Significant correlation of III and IV fibrosis stages with HA level has been found [7-9]. There have been suggested various indices based on a ratio of some clinical biochemical measurements: FibroTest and FibroMether (France), APRI (USA) and some others, hepatic elastography being developed [10-12].

Recently, many research works are devoted to cytokine status determination in $\mathrm{CHC}$. According to the authors [13-15], increased serum levels of antiinflammatory cytokines are consistent with a high degree of inflammation and fibrotic changes in hepatic tissue.

Unfortunately, the existing technologies of noninvasive diagnostics of fibrosis in the liver do not always enable to differentiate stages at an early $\mathrm{CHC}$ due to the absence of significant differences, the

For contacts: Irina A. Bulatova, e-mail: bula.1977@mail.ru 
technologies being of great diagnostic importance in severe fibrosis and cirrhosis. The combination of elastography and laboratory tests increases the accuracy of fibrosis extent assessment [16].

Taking into consideration the fact that $\mathrm{CHC}$ progression and the mechanism of fibrosis development in the liver are due to a diversity of morphological hepatic response to damage (steatosis, pigment depositions, thrombosis, apoptosis, necrosis, adaptation, hepatocyte proliferation and proper fibrous changes [17]), it seemed to be interesting to carry out an integrated study of laboratory markers of various pathogenetic mechanisms participating in $\mathrm{CHC}$ progression.

The aim of the investigation was to assess the availability of a combined study of biochemical tests, hyaluronic acid, alpha-fetoprotein, malondialdehyde, catalase, cytokines, and leptin to determine the liver damage severity (fibrosis and cirrhosis stages) in patients with chronic hepatitis $\mathrm{C}$.

Materials and Methods. The study involved 100 patients (48 males and 52 females) with reactive $\mathrm{CHC}$. The research was carried out in Infectious Department No.2, Perm Territorial Clinical Infectious Hospital. Mean patients' age was $39.5 \pm 10.2$ years. A control group compatible in sex and age included of 30 apparently healthy subjects.

The study was carried out in accordance with the Declaration of Helsinki (adopted in June 1964, Helsinki, Finland, and revised in October 2000, Edinburg, Scotland) and was approved by the Ethics Committee of Perm State Medical University named after Academician E.A. Wagner. All patients gave their written informed consent.

Body mass index (BMI) in $\mathrm{CHC}$ patients was calculated. $\mathrm{CHC}$ was diagnosed on the basis of the findings of a complex of clinical laboratory and instrumental examinations. Hepatic density and fibrosis stage were determined by ultrasound elastography (UE) on FibroSkan 502 (Echosens, France). RNA of hepatitis $C$ virus was revealed and quantified by polymerase chain reaction using an amplifier Real-time CFX96 (Bio-Rad Laboratories, USA) and a Vector-Best kit (Novosibirsk).

Biochemical parameters of blood serum were estimated by a biochemical analyzer Architect c4000 (Abbott Laboratories, USA) using similarly-named kits to determine alanine aminotransferase (ALT), aspartate aminotransferase (AST) (Abbott Clinical Chemistry; Abbott Laboratories, USA), and albumin - by an Albumin-Novo kit (Vector-Best, Novosibirsk). Platelet count was assessed by an automatic hematology analyzer Medonic M20 (Boule Medical AB, Sweden).

$\mathrm{HA}$ concentration was studied in blood serum of $\mathrm{CHC}$ patients by enzyme immunoassay on a photometer Stat Fax 2100 (Awareness Technology, USA) using BCM Diagnostics kit (USA), tumor necrosis factor- $\alpha$ (TNF- $\alpha$ ) and vascular endothelial growth factor (VEGF) - using the similarly-named kits by Vector-Best (Novosibirsk), leptin - by DSL kit (ACTIV, USA). Alpha-fetoprotein
(AFP) level was estimated as a hepatocyte regeneration test by chemiluminescent immunoassay using AFP kit on an analyzer Immulite-1000 (Siemens, Germany). Malondialdehyde (MDA) concentration in blood serum was determined according to Vladimirov, Archakov technique (1972). Catalase activity was studied by photometry according to Korolyuk method (1988).

The findings were statistically processed using Statistica 6.0 (StatSoft), the results being represented as mean and standard deviation $(\mathrm{M} \pm \sigma)$. Mann-Whitney test was used to determine statistical significance of differences. A linear relationship between two independent variables was quantitatively assessed using Spearman's rank correlation coefficient $(r)$. Sample differences were considered significant if $p<0.05$.

Results and Discussion. In $\mathrm{CHC}$ patients BMI had no significant variations from controls $(p=0.81)$, however, $11 \%$ from 100 subjects examined were found to have excess BMI consistent with overweight, and $4 \%$ patients had abdominal obesity signs. Generally, in $\mathrm{CHC}$ group, liver density averaged $9.6 \pm 9.5$ (from 3.1 to 63.9 ) $\mathrm{kPa}$ according to UE. Low viral load was recorded in $31 \%$ $\mathrm{CHC}$ patients, high viral load - in 69\%. According to laboratory tests, the patients with reactive $\mathrm{CHC}$ appeared to have significantly increased levels of ALT and AST transaminases suggesting cytolysis syndrome $(p<0.001$ and $p<0.001)$. Albumin in blood serum had no significant differences from that of a control group $(p=0.76)$, hypoalbuminemia being recorded in $18 \%$ of the subjects under study. A reduced platelet count was found in $16 \%(p=0.04)$.

The analysis of direct laboratory marker of liver fibrosis (HA in blood serum) showed its significant increase by 2.2 times in $50 \%$ patients $(p=0.01)$. AFP, a hepatocyte regeneration marker, was 2.5 times as high in $21 \%$ patients with $\mathrm{CHC}(\mathrm{p}=0.02)$. The activation of lipid peroxidation processes was found in $80 \%$ patients, it manifesting in significant increase of MDA concentration: by 4 times compared to a control group $(p<0.001)$. The analysis of catalase, an antioxidant enzyme, in $\mathrm{CHC}$ patients revealed the decrease of MDA activity by 1.6 times $(p<0.001)$. According to enzyme immunoassay, VEGF concentration in blood serum was 4 times higher in $82 \%$ and TNF- $\alpha$ was 11 times as high in $85 \%$ patients with $\mathrm{CHC}(p<0.001$ and $p=0.001)$. Hyperleptinemia was found in $13 \%$ patients $(p=0.001)$. Table 1 shows the comparative analysis findings of the parameters under study in $\mathrm{CHC}$ patients and controls.

Thus, CHC reactivation is accompanied by the increase in viral load, necroinflammatory changes in the liver, the decrease of albumin level and platelet count, the activation of immuno-inflammatory processes and lipid peroxidation in associated depletion of antioxidant protection, neoangiogenesis and fibrinogenesis enhancement in the liver with hepatocyte regeneration activation that is consistent with the findings of other studies [7-9, 13-15, 18, 19], where these parameters were analyzed separately. 
Table 1

Studied blood serum indices in patients with chronic hepatitis $C$ in a control group and in chronic hepatitis $C$ depending on the presence of cytolysis $(M \pm \sigma)$

\begin{tabular}{lcccc}
\hline \multicolumn{1}{c}{ Parameters } & $\begin{array}{c}\text { Control } \\
(\mathrm{n}=30)\end{array}$ & $\begin{array}{c}\text { Chronic } \\
\text { hepatitis C }(\mathrm{n}=100)\end{array}$ & $\begin{array}{c}\text { No cytolysis } \\
\text { group }(\mathrm{n}=32)\end{array}$ & $\begin{array}{c}\text { Cytolysis } \\
\text { group (n=68) }\end{array}$ \\
\hline Age (years) & $37.3 \pm 8.1$ & $39.5 \pm 10.2$ & $41.9 \pm 10.3$ & $36.4 \pm 9.2^{+}$ \\
\hline Body mass index & $24.3 \pm 4.2$ & $24.7 \pm 4.7$ & $23.6 \pm 5.1$ & $25.6 \pm 4.5^{+}$ \\
\hline Liver density $(\mathrm{kPa})$ & - & $9.6 \pm 9.5$ & $9.5 \pm 10.1$ & $9.7 \pm 8.5$ \\
\hline Viral load $\left(\times 10^{6} / \mathrm{U} / \mathrm{ml}\right)$ & - & $8.9 \pm 15.3$ & $4.7 \pm 5.9$ & $12.2 \pm 18.5^{+}$ \\
\hline ALT $(\mathrm{U} / \mathrm{L})$ & $17.4 \pm 8.6$ & $82.6 \pm 73.3^{*}$ & $31.1 \pm 10.1$ & $80.7 \pm 24.8^{+}$ \\
\hline AST $(\mathrm{U} / \mathrm{L})$ & $22.1 \pm 7.3$ & $52.9 \pm 45.8^{*}$ & $28.1 \pm 12.8$ & $51.3 \pm 23.1^{+}$ \\
\hline Albumin $(\mathrm{g} / \mathrm{L})$ & $46.3 \pm 2.35$ & $46.1 \pm 4.5$ & $46.2 \pm 4.6$ & $46.1 \pm 4.4$ \\
\hline Platelets $\left(\times 10^{9} / \mathrm{L}\right)$ & $307.1 \pm 36.1$ & $249.8 \pm 72.9^{*}$ & $264.8 \pm 74.7$ & $239.0 \pm 69.1^{+}$ \\
\hline Hyaluronic acid $(\mathrm{ng} / \mathrm{ml})$ & $24.2 \pm 20.1$ & $52.7 \pm 68.1^{*}$ & $49.8 \pm 54.6$ & $54.2 \pm 71.3$ \\
\hline Alpha-fetoprotein $(\mathrm{IU} / \mathrm{ml})$ & $1.2 \pm 0.5$ & $3.2 \pm 3.5^{*}$ & $2.4 \pm 1.5$ & $3.6 \pm 4.6^{+}$ \\
\hline Malondialdehyde $(\mu \mathrm{mol} / \mathrm{L})$ & $2.1 \pm 1.1$ & $8.4 \pm 4.1^{*}$ & $8.6 \pm 4.2$ & $8.2 \pm 3.9$ \\
\hline Catalase $(\mathrm{mkat} / \mathrm{L})$ & $26.6 \pm 6.7$ & $11.6 \pm 7.7^{*}$ & $12.4 \pm 6.9$ & $10.8 \pm 7.9^{+}$ \\
\hline VEGF $(\mathrm{pg} / \mathrm{ml})$ & $101.4 \pm 98.3$ & $419.4 \pm 304.0^{*}$ & $412.4 \pm 298.0$ & $424.0 \pm 311.0$ \\
\hline TNF- $\alpha(\mathrm{pg} / \mathrm{ml})$ & $0.4 \pm 0.6$ & $4.5 \pm 9.0^{*}$ & $3.4 \pm 5.6$ & $5.6 \pm 12.1^{+}$ \\
\hline Leptin $(\mathrm{ng} / \mathrm{ml})$ & $2.3 \pm 1.7$ & $4.3 \pm 2.9^{*}$ & $4.2 \pm 2.8$ & $4.5 \pm 2.9$ \\
\hline
\end{tabular}

* Significant difference of values in groups of patients with chronic hepatitis $\mathrm{C}$ and controls;

+ in groups of patients with and without cytolysis; $p<0.05$.

At the next stage, all the patients were divided into two subgroups to compare the factors under study in $\mathrm{CHC}$ depending on the presence of cytolysis. A subgroup without cytolysis with normal values of transaminases involved 32 patients, their mean age being $43.6 \pm 10.9$ years, a cytolysis group included 68 patients aged $36.4 \pm 9.2$ years $(p=0.004)$ (See Table 1$)$. The patients with increased levels of transaminases were found to have higher BMI $(p=0.02)$, viral load $(p=0.01)$, significantly increased concentrations of AFP $(p=0.03)$ and antiinflammatory cytokine TNF- $\alpha(p=0.01)$ depending on a cytolytic syndrome in $\mathrm{CHC}$. The obtained data indicate the association of cytolysis with younger age, enhancement of replication viral activity, activation of immunoinflammatory mechanisms and hepatocyte regeneration. Moreover, these $\mathrm{CHC}$ patients appeared to have significant decrease in platelet count $(p=0.04)$ and catalase (an antioxidant enzyme) activity compared to the patients with a normal level of serum transaminases (i.e. in a group without cytolysis), it indicating the presence of a dependence of biological factors of the parameters on the concentration of cytolysis markers, the findings prompting suggestions that the increase in viral load, AFP, and TNF- $\alpha$, as well as the decrease of catalase activity and platelet count contribute to aggravation of progressing necroinflammatory changes in the liver, and their serum concentration in $\mathrm{CHC}$ patients indicates the severity of liver tissue damage, it enables to use the factors as additional markers to assess the process activity.

During the third stage, it was interesting to determine the concentration of the factors under study in $\mathrm{CHC}$ patients due to a liver fibrosis stage (Table 2).

Table 2 shows the concentration of the studied factors in blood serum of $\mathrm{CHC}$ patients to change mostly according to liver fibrosis progression. Initial and moderate fibrosis (FI-II) in $\mathrm{CHC}$ from F0 stage can be differentiated by the following blood parameters: viral load level $(p=0.01)$, platelet count $(p=0.01)$, HA level $(p=0.002)$ and the concentration of VEGF $(p=0.03)$ and TNF- $\alpha(p=0.01)$.

Marked liver fibrosis (FIII) from moderate fibrosis (FI-II) in $\mathrm{CHC}$ patients can be diagnosed by such parameters as: age $(p=0.03)$, BMl $(p=0.02)$, increased levels of ALT ( $p=0.02)$, AST $(p=0.02), H A(p=0.02), A F P$ $(p=0.04)$, VEGF $(p=0.01)$ and TNF- $\alpha(p=0.03)$ in blood serum in decreased levels of albumin $(p=0.01)$, catalase $(p=0.03)$, and platelet count $(p=0.002)$.

Cirrhosis stage (FIV) in $\mathrm{CHC}$ can be stratified, as well as differentiated from marked fibrosis (FIII) by the alteration of the following laboratory parameters: the increase of viral load $(p=0.01)$, albumin reduction $(p=0.01)$, a significant increase of HA $(p=0.01)$, AFP $(p=0.03), \operatorname{MDA}(p=0.02)$, TNF- $\alpha(p=0.03)$, and leptin $(p=0.02)$.

Thus, serum markers of $H A$ and TNF- $\alpha$ enable 
Table 2

The studied blood serum parameters $(M \pm \sigma)$ in patients with chronic hepatitis $C$ depending on liver fibrosis stage (F)

\begin{tabular}{|c|c|c|c|c|}
\hline Parameters & Fo (n=31) & $\mathrm{FI}-\mathrm{II}(\mathrm{n}=50)$ & FIII $(n=8)$ & FIV (n=11) \\
\hline Age (years) & $37.8 \pm 9.8$ & $39.5 \pm 9.8$ & $43.6 \pm 10.9^{+}$ & $43.4 \pm 9.8$ \\
\hline Body mass index & $24.3 \pm 4.5$ & $23.6 \pm 4.1$ & $28.6 \pm 5.1^{+}$ & $27.8 \pm 4.9$ \\
\hline Liver density (kPa) & $4.8 \pm 0.7$ & $7.4 \pm 1.2^{*}$ & $12.1 \pm 1.7^{+}$ & $31.0 \pm 16.9^{v}$ \\
\hline Viral load (×106/U/ml) & $12.4 \pm 21.3$ & $4.7 \pm 3.7^{*}$ & $4.8 \pm 1.1$ & $22.4 \pm 14.2^{v}$ \\
\hline $\operatorname{ALT}(\mathrm{U} / \mathrm{L})$ & $74.2 \pm 61.8$ & $62.2 \pm 44.4$ & $117.6 \pm 108.0^{+}$ & $91.8 \pm 50.9$ \\
\hline AST (U/L) & $45.1 \pm 33.7$ & $41.1 \pm 27.3$ & $78.5 \pm 71.0^{+}$ & $79.6 \pm 46.9$ \\
\hline Albumin (g/L) & $48.1 \pm 3.8$ & $47.5 \pm 2.9$ & $42.0 \pm 4.1^{+}$ & $38.1 \pm 5.5^{v}$ \\
\hline Platelets (×109/L) & $288.0 \pm 64.2$ & $245.0 \pm 70.7^{*}$ & $170.5 \pm 36.7^{+}$ & $163.0 \pm 50.1$ \\
\hline Hyaluronic acid (ng/ml) & $25.6 \pm 13.1$ & $44.4 \pm 26.1^{*}$ & $83.1 \pm 65.9^{+}$ & $240.0 \pm 173.4^{v}$ \\
\hline Alpha-fetoprotein (IU/ml) & $2.2 \pm 1.1$ & $2.4 \pm 1.2$ & $3.9 \pm 1.7^{+}$ & $6.9 \pm 7.7^{v}$ \\
\hline Malondialdehyde $(\mu \mathrm{mol} / \mathrm{L})$ & $8.6 \pm 7.1$ & $7.8 \pm 3.8$ & $7.7 \pm 3.2$ & $9.1 \pm 3.1^{v}$ \\
\hline Catalase (mkat/L) & $10.9 \pm 6.3$ & $11.5 \pm 6.9$ & $8.1 \pm 4.2^{+}$ & $8.9 \pm 4.7$ \\
\hline VEGF (pg/ml) & $386.6 \pm 286$ & $496.0 \pm 337.0^{*}$ & $643.0 \pm 118.0^{+}$ & $573.0 \pm 109.0$ \\
\hline TNF- $\alpha$ (pg/ml) & $2.1 \pm 2.6$ & $4.3 \pm 10.3^{*}$ & $5.5 \pm 9.5^{+}$ & $13.7 \pm 14.6^{v}$ \\
\hline Leptin (ng/ml) & $3.8 \pm 3.1$ & $4.2 \pm 2.9$ & $4.5 \pm 3.1$ & $6.9 \pm 3.5^{v}$ \\
\hline
\end{tabular}

* Significant difference of values in groups with $\mathrm{FI}-\mathrm{Il}$ and with $\mathrm{F0}$; ${ }^{+}$in groups with FIII and $\mathrm{FI}-\mathrm{Il}$;

$\checkmark$ in groups with FIV and FIII; $p<0.05$.

to stratify all fibrosis stages in the liver in $\mathrm{CHC}$ that is confirmed by direct significant correlations with liver density according to UE $(r=0.42 ; p=0.001$ and $r=0.41$; $p=0.001$, respectively). The most pronounced increase of AFP, VEGF, and MDA in a simultaneous decrease of albumin synthesis, catalase activity, and a platelet level are found in all stages of severe fibrosis. It is confirmed by the presence of direct and indirect reliable relationships with liver density values for AFP $(r=0.43$; $p=0.001)$ and VEGF ( $r=0.40 ; p=0.001)$ and invert correlations for albumin $(r=-0.59 ; p=0.001)$ and platelets $(r=-0.56 ; p=0.001)$.

The findings and revealed correlation regularities enable to suggest the serum concentrations of HA and TNF- $\alpha$ in $\mathrm{CHC}$ patients to indicate the liver damage severity and can be used to stratify liver fibrosis stages. The data, to a certain extent, are consistent with the results obtained by other authors, who confirmed the compliance of increased HA and TNF- $\alpha$ levels in blood with fibrosis extent in hepatic tissue [7-9, 1315]. According to Yushchuk et al. [7], the diagnostic efficiency of HA to stratify FIII stage in chronic hepatitis from FIV in hepatic cirrhosis has $100 \%$ sensitivity and $84.6 \%$ specificity. According to Lobzin et al. [8], HA determination in blood serum enables to differentiate severe fibrosis and cirrhosis only $(70.7 \pm 11.7$ and $258.2 \pm 95.7 \mathrm{ng} / \mathrm{ml}$, if $\mathrm{p}<0.01)$, while there are no significant differences between FII and FIII.

Conclusion. Progressive $\mathrm{CHC}$ and liver fibrosis are accompanied by the activation of pathological regeneration of hepatocytes and neoangiogenesis, lipid peroxidation enhancement and depleted antioxidant protection, inflammation activity enhancement, metabolic disturbances, and characterized by the increase in $\mathrm{HA}$, AFP, MDA, VEGF, TNF- $\alpha$, and leptin content in blood and a simultaneous decrease in albumin synthesis, platelet count and reduced catalase activity. Serum concentrations of $\mathrm{HA}$ and TNF- $\alpha$ in $\mathrm{CHC}$ patients indicate the extent of liver tissue damage and can be used to stratify liver fibrosis stages. The determination of AFP, VEGF, MDA albumin, catalase, leptin concentration and platelet count can be used as accessory tests to diagnose advanced fibrosis (FII-FIV stages) in patients with $\mathrm{CHC}$. The assessment of serum leptin level can be applied to differentiate hepatic cirrhosis from fibrosis (FIFIII).

Study Funding. The work was carried out at authors' expense, and also was supported by Vector-Best (Novosibirsk).

Conflicts of Interest. Vector-Best (Novosibirsk) had no impact on the research course and its results.

\section{References}

1. Ivashkin V.T., Yushchuk N.D., Maevskaya M.V. Hepatitis C diagnostics and treatment guidelines in adults. Rossiyskiy zhurnal gastroenterologii, gepatologii $i$ koloproktologii 2013; 2: 41-70. 
2. Pimenov N.N., Chulanov V.P., Komarova S.V., Karandashova I.V., Neverov A.D., Mikhailovskaya G.V., Dolgin V.A., Lebedeva E.B., Pashkina K.V., Korshunova G.S. Hepatitis C in Russia: current epidemiology and approaches to improving diagnosis and surveillance. Epidemiologiya $i$ infektsionnye bolezni 2012; 3: 4-10.

3. Alter M.J. Epidemiology of hepatitis $C$ virus infection. World J Gastroenterol 2007; 13(17): 2436, https://doi. org/10.3748/wjg.v13.i17.2436.

4. Perz J.F., Grytdal S., Beck S., Fireteanu A.M., Poissant T., Rizzo E., Bornschlegel K., Thomas A., Balter S., Miller J., Klevens R.M., Finelli L. Case-control study of hepatitis B and hepatitis C in older adults: do healthcare exposures contribute to burden of new infections? Hepatology 2013; 57(3): 917-924, https://doi.org/10.1002/hep.25688.

5. Szymczak A., Simon K., Inglot M., Gladysz A. Safety and effectiveness of blind percutaneous liver biopsy: analysis of 1412 procedures. Hepat Mon 2012; 12(1): 32-37, https:// doi.org/10.5812/kowsar.1735143x.810.

6. Liu T., Wang X., Karsdal M.A., Leeming D.J., Genovese F. Molecular serum markers of liver fibrosis. Biomark Insights 2012; 7: 105-107, https://doi.org/10.4137/ bmi.s10009.

7. Yushchuk N.D., Znoyko O.O., Safiullina N.Kh., Kelli E.I. Liver needle biopsy and possibilities of noninvasive fibrosis monitoring in chronic viral hepatitis C. Klinicheskie perspektivy gastroenterologii, gepatologii 2002; 1: 9-16.

8. Lobzin Yu.V., Zhdanov K.V., Gusev D.A., Strel'tsov A.G., Golubin B.V. Serologic markers of fibrosis in diagnosing and treatment of chronic hepatitis C. Infektsionnye bolezni 2005; 3(3): 28-30.

9. Yamada M., Fukuda Y., Nakano I., Katano Y., Takamatsu J., Hayakawa T. Serum hyaluronan as a marker of liver fibrosis in hemophiliacs with hepatitis $C$ virus-associated chronic liver disease. Acta Haematol 1998; 99(4): 212-216, https://doi.org/10.1159/000040841.

10. Pavlov Ch.S., Glushenkov D.V., Ivashkin V.T. Modern potentials of elastometry, fibro-and acti-test in diagnostics of liver fibrosis. Rossiyskiy zhurnal gastroenterologii, gepatologii, koloproktologii 2008; 18(4): 43-52.

11. Pavlov Ch.S., Glushenkov D.V., Konovalova O.N., Ivaskin V.T. The scope of clinical applications of non-invasive methods for the assessment of liver fibrosis: results of original studies in a multi-field hospital. Klinicheskaya meditsina 2009; 87(11): 40-45.

12. Sebastiani G., Halfon P., Castera L., Mangia A.,
Di Marco V., Pirisi M., Voiculescu M., Bourliere M., Alberti A. Comparison of three algorithms of non-invasive markers of fibrosis in chronic hepatitis C. Aliment Pharmacol Ther 20121; 35(1): 92104, https://doi.org/10.1111/j.1365-2036.2011.04897.x.

13. Falleti E., Fabris C., Toniutto P., Fontanini E., Cussigh A., Caldato M., Rossi E., Bitetto D., Minisini R., Smirne C., Pirisi M. Genetic polymorphisms of inflammatory cytokines and liver fibrosis progression due to recurrent hepatitis C. J Interferon Cytokine Res 2007; 27(3): 239-246, https://doi.org/10.1089/jir.2006.0062.

14. Li K., Li N.L., Wei D., Pfeffer S.R., Fan M., Pfeffer L.M. Activation of chemokine and inflammatory cytokine response in hepatitis $C$ virus-infected hepatocytes depends on toll-like receptor 3 sensing of hepatitis $C$ virus double-stranded RNA intermediates. Hepatology 2012; 55(3): 666-675, https://doi. org/10.1002/hep.24763.

15. Farci P., Wollenberg K., Diaz G., Engle R.E., Lai M.E., Klenerman P., Purcell R.H., Pybus O.G., Alter H.J. Profibrogenic chemokines and viral evolution predict rapid progression of hepatitis C to cirrhosis. Proc Natl Acad Sci USA 2012; 109(36): 14562-14567, https://doi.org/10.1073/ pnas.1210592109.

16. Zarski J.P., Sturm N., Guechot J., Paris A., Zafrani E.S., Asselah T., Boisson R.C., Bosson J.L., Guyader D., Renversez J.C., Bronowicki J.P., Gelineau M.C., Tran A., Trocme C., De Ledinghen V., Lasnier E., Poujol-Robert A., Ziegler F., Bourliere M., Voitot H., Larrey D., RosenthalAllieri M.A., Fouchard Hubert I., Bailly F., Vaubourdolle M.; ANRS HCEP 23 Fibrostar Group. Comparison of nine blood tests and transient elastography for liver fibrosis in chronic hepatitis C: the ANRS HCEP-23 study. J Hepatology 2012; 56(1): 55-62, https://doi.org/10.1016/j.jhep.2011.05.024.

17. Mekhtiev S.N., Stepanenko V.V., Zinovieva E.N., Mekhtieva O.A. Modern concepts of liver fibrosis and methods of its correction. Farmateka 2014; 6(279): 80-87.

18. Zhdanov K.V., Gusev D.A., Pastushenkov V.L., Shkuro A.V. Serum content of a-fetoprotein in patients with chronic hepatitis C during interferon therapy. Rossiyskiy zhurnal gastroenterologii, gepatologii, koloproktologii 2004; 14(1, Suppl): 12.

19. Geyvandova N.I., Yagoda A.V., Gudzovskaya D.A., Kostornaya I.V. Serum phospholipids, lipid peroxidation scores and antioxidative protection as additional non-invasive markers of chronic viral hepatitis $\mathrm{C}$ activity. Rossiyskiy zhurnal gastroenterologii, gepatolologii, koloproktologii 2008; 18(6): 38-43. 